\title{
CRISPR/Cas9-based generation of a recombinant double-reporter pseudorabies virus and its characterization in vitro and in vivo
}

\author{
Peng-Fei Fu ${ }^{\dagger}$, Xuan Cheng ${ }^{\dagger}$, Bing-Qian Su, Li-Fang Duan, Cong-Rong Wang, Xin-Rui Niu, Jiang Wang, \\ Guo-Yu Yang ${ }^{*}$ and Bei-Bei Chu* (1)
}

\begin{abstract}
Pseudorabies, caused by pseudorabies virus (PRV) variants, has broken out among commercial PRV vaccine-immunized swine herds and resulted in major economic losses to the pig industry in China since late 2011. However, the mechanism of virulence enhancement of variant PRV is currently unclear. Here, a recombinant PRV (rPRV HN1201EGFP-Luc) with stable expression of enhanced green fluorescent protein (EGFP) and firefly luciferase as a double reporter virus was constructed on the basis of the PRV variant HN1201 through CRISPR/Cas9 gene-editing technology coupled with two sgRNAs. The biological characteristics of the recombinant virus and its lethality to mice were similar to those of the parental strain and displayed a stable viral titre and luciferase activity through 20 passages. Moreover, bioluminescence signals were detected in mice at $12 \mathrm{~h}$ after rPRV HN1201-EGFP-Luc infection. Using the double reporter PRV, we also found that 25-hydroxycholesterol had a significant inhibitory effect on PRV both in vivo and in vitro. These results suggested that the double reporter PRV based on PRV variant HN1201 should be an excellent tool for basic virology studies and evaluating antiviral agents.
\end{abstract}

Keywords: Pseudorabies virus, Firefly luciferase, EGFP, CRISPR/Cas9, Imaging in vivo, 25-hydroxycholesterol

\section{Introduction}

Pseudorabies virus (PRV), belonging to the Herpesviridae family, subfamily Alphaherpesvirinae, genus Varicellovirus, is the aetiological agent of pseudorabies and was first described in 1813 [1-3]. PRV is a neurotropic herpesvirus that can establish latent infection in nerve cells [4-6]. This virus can cause severe encephalitis in juvenile pigs [7] and various non-native hosts [8-10]. In non-native hosts such as mice, PRV infection is always lethal [11]. Owing to the use of the PRV vaccine strain Bartha-K61 from Hungary, which contains a complete deletion of the regions encoding glycoprotein $\mathrm{E}(\mathrm{gE})$ and US9 and partial

*Correspondence: haubiochem@163.com; chubeibei@henau.edu.cn ${ }^{\dagger}$ Peng-Fei Fu and Xuan Cheng contributed equally to this work College of Veterinary Medicine, Henan Agricultural University, Zhengzhou 450046, Henan, China deletion within the gI and US2 coding regions, pseudorabies (PR) was well controlled on most pig farms in China between the 1990s and 2011 [12]. However, in late 2011, PR re-emerged in many pig herds immunized with the Bartha-K61 PRV vaccine in North China and spread rapidly across various provinces $[13,14]$. Novel PRV variants have been found in the swine population of China [13, 15-20]. In addition, some human cases of viral endophthalmitis and encephalitis caused by PRV infection have been reported in China [21-25]. Given the urgency of the epidemic and PRV's potential threat to human health, further research on PRV variants is critical.

Viral reverse genetics technology plays an important role in PRV vaccine development and pathogenicity research [26-28]. The genome of PRV is a linear doublestranded DNA approximately 150 kilobases kb in length, encoding 70 proteins [1]; it includes many nonessential 
regions for replication in cell culture, such as the TK, PK, gI, gE, gC and gG genes $[2,29,30]$. These characteristics allow PRV to accommodate several $\mathrm{kb}$ of foreign DNA without affecting its stability. The traditional methods for editing PRV, homologous recombination (HR) and bacterial artificial chromosome (BAC) construction, are both laborious and time-consuming [31-33]. Clustered regulatory interspaced short palindromic repeats/ CRISPR-associated protein 9 (CRISPR/Cas9) is an adaptive immune mechanism that evolved in archaea and bacteria [34]. This system has been developed as a powerful DNA engineering tool in diverse organisms. In this study, a recombinant virus (rPRV HN1201-EGFP-Luc) for stable expression of enhanced green fluorescent protein (EGFP) and firefly luciferase was constructed on the basis of the PRV variant HN1201 by using a two sgRNA CRISPR/Cas9 system and was applied to investigate the inhibitory effect of 25-hydroxycholesterol (25-HC) on PRV proliferation in PK-15 cells and in mice. The double reporter PRV carrying EGFP and firefly luciferase in this study enabled convenient quantification and tracing of PRV in vitro and in vivo.

\section{Materials and methods \\ Mice}

The Animal Care Committee of Henan Agricultural University (Zhengzhou, People's Republic of China) approved this study (Approval Number 11-0085), and all animals were maintained in a specific-pathogen-free animal facility according to the related ethical regulations at Henan Agricultural University and the guide for the care and use of laboratory animals.

Female 6-8-week-old BALB/c mice were purchased from the Center of Experimental Animal of Zhengzhou University (Zhengzhou, China) and maintained in a specific pathogen-free animal facility according to the guide for the care and use of laboratory animals and the related ethical regulations at Henan Agricultural University.

\section{Cell lines and viruses}

PK-15, ST and 3D4/21 cells were cultured in Dulbecco's modified Eagle's medium (DMEM) (Gibco, Grand Island, NY, USA) supplemented with $10 \%(\mathrm{v} / \mathrm{v})$ foetal bovine serum (FBS; Gibco) at $37{ }^{\circ} \mathrm{C}$ with $5 \% \mathrm{CO}_{2}$. The PRV variant HN1201 (GenBank Accession No. KP722022) was a kind gift from Ke-gong Tian at the College of Veterinary Medicine, Henan Agricultural University [16].

\section{Generation of the donor plasmid and double sgRNA CRISPR/Cas9 plasmid}

To construct the plasmid pX459M-sgRNA1-sgRNA2, we obtained small guide RNA1 (sgRNA1) targeting PRV gI from the annealing product of sgRNA1-Fwd and
sgRNA1-Rev oligos and inserted it into the $\mathrm{pX} 459 \mathrm{M}$ vector (Addgene, Watertown, MA, USA) at the BbsI site to produce the recombinant plasmid pX459M-sgRNA1. The sgRNA2-Fwd and sgRNA2-Rev sequences were annealed to form sgRNA2 targeting PRV gE and cloned into the pEZ-Guide-XH vector at the BbsI site. Then, sgRNA2 was obtained from the pEZ-Guide-XH vector via the $X h o \mathrm{I}$ and HindIII sites and inserted into the plasmid pX459MsgRNA1 to yield the recombinant plasmid pX459MsgRNA1-sgRNA2. Two sgRNAs for editing PRV were used in this study and are listed in Table 1 . There were no potential off-target regions for sgRNA1 and sgRNA2 in the PRV genome, as determined by using CRISPR [35].

To obtain the donor plasmid pUC57-US6/7-EGFP-LucUS8/9, we synthesized DNA fragments containing EcoRI, EcoRV, PacI, XhoI, BamHI, NheI and HindIII sites and inserted them into the pUC57 vector between the EcoRI and HindIII sites to replace the multiple cloning site of the pUC57 vector. The right HR arm (including the partial US8 gene and the entire US9 gene of PRV HN1201) was amplified from the PRV HN1201 genome with the US 8/9-F/R primer set and inserted into the pUC57 vector between the BamHI and NheI sites to construct the recombinant plasmid pUC57-US8/9. The firefly luciferase expression cassette was removed from the pGL3Control vector with $\mathrm{XhoI}$ and $\mathrm{BamHI}$ and inserted into the plasmid pUC57-US8/9, thus generating the recombinant plasmid pUC57-Luc-US8/9. Then, the EGFP expression cassette was released from the CBh-EGFP vector via

Table 1 Sequences of the primers and sgRNAs utilized in this study

\begin{tabular}{ll}
\hline Primers and sgRNAs & Sequences (5'-3') \\
\hline US 6/7-F & 5'-GAATTCCGGCGTGAACATCCTCACCGACT-3' \\
US 6/7-R & 5'-GATATCGCAGCGTCCCGTCTATCGTCAGGT-3' \\
US 8/9-F & 5'-GGATCCGCCCACGCACGAGGACTACTACGA-3' \\
US 8/9-R & 5'-GCTAGCGGTGGAGGCGGTGGAGAAGAAGAG-3' \\
sgRNA1-F & 5'-CACCGTCGTGCCACGATCCGACGA-3' \\
sgRNA1-R & 5'-AAACTCGTCGGATCGTGGCACGAC-3' \\
sgRNA2-F & 5'-CACCGTACAGCCCCGACTCGTCCG-3' \\
sgRNA2-R & 5'-AAACCGGACGAGTCGGGGCTGTAC-3' \\
U6-F & 5'-CTATTTCCCATGATTCCTTCA-3' \\
CAG-screen R & 5'-GTACTGGGCACAATGCCAG-3' \\
Porcine actin-F & 5'-CTGAACCCCAAAGCCAACCGT-3' \\
Porcine actin-R & 5'-TTCTCCTTGATGTCCCGCACG-3' \\
Porcine IFN- $\beta-F$ & 5'-AGTTGCCTGGGACTCCTCAA -3' \\
Porcine IFN- $\beta-R$ & 5'-CCTCAGGGACCTCAAAGTTCAT-3' \\
Porcine IL-1 $\beta-F$ & 5'-CCATCCACTGAGCCAGCCTT-3' \\
Porcine IL-1 $\beta-R$ & 5'-TGCCAAGGACAGAGGACTGC-3' \\
LuC-F & 5'-ATGGAAGACGCCAAAAACATAAAG-3' \\
Luc-R & 5'-TTACACGGCGATCTTTCCGCCCT-3' \\
\hline
\end{tabular}


the PacI site and cloned into the recombinant plasmid pUC57-Luc-US8/9 to generate the recombinant plasmid pUC57-EGFP-Luc-US8/9. The left HR arm (including the partial US6 gene and partial US7 gene of PRV HN1201) was amplified from the PRV HN1201 genome with the US 6/7-F/R primer set and then inserted into the recombinant plasmid pUC57-EGFP-Luc-US8/9 between the EcoRI and EcoRV sites to obtain the donor plasmid pUC57-US6/7-EGFP-Luc-US8/9. Sequences of all plasmids constructed in the study were confirmed by Sanger sequencing.

\section{Generation of double reporter PRV}

The PRV HN1201 genome was extracted as previously described $[15,36]$. A total of $2 \mu \mathrm{g}$ of donor plasmid pUC57-US6/7-EGFP-Luc-US8/9 was cotransfected into PK-15 cells together with $1 \mu \mathrm{g}$ of two-sgRNA CRISPR/ Cas9 plasmid pX459M-sgRNA1-sgRNA2 and $1 \mu \mathrm{g}$ of the PRV HN1201 genome by using Lipofectamine 2000 (Invitrogen, USA) according to the manufacturer's instructions. EGFP was detected by using a standard FITC filter-equipped fluorescence microscope (Nikon Eclipse TS100) at 2-3 days after cotransfection. When cytopathic effects (CPEs) appeared, the cells were collected. The cell lysate was serially diluted $10^{-1}-10^{-8}$ fold and used to infect PK-15 cell monolayers in a 96-well cell culture plate. The recombinant virus was purified from the 96-well cell culture plate with an endpoint dilution assay under an inverted fluorescence microscope. After three virus purification steps and further luciferase assays, the recombinant virus was obtained and named rPRV HN1201-EGFP-Luc. The genomic DNA of rPRV HN1201-EGFP-Luc was extracted from cell lysates to amplify the expected fragment (including the left HR arm, the EGFP expression cassette, the firefly luciferase expression cassette and the right HR arm) with the primers US 6/7-F and US 8/9-R (Table 1), and PCR products were sequenced for identification of the recombinant virus.

\section{PCR and $q P C R$}

PK-15 cells were harvested at specific times after PRV HN1201 or rPRV HN1201-EGFP-luc infection, and then, total RNA was extracted from PK-15 cells by using TRIzol reagent (9108, TaKaRa). cDNA was synthesized from the total RNA with a PrimeScript RT reagent Kit (RR047A, TaKaRa). qPCR was performed in triplicate by using SYBR Premix Ex Taq (RR820A, TaKaRa) according to the manufacturer's instructions, and data were normalized to the level of $\beta$-actin expression in each sample. Melting curve analysis indicated the formation of a single product in all cases. Porcine IL- $\beta$, IFN- $\beta$ and actin gene expression was detected with the primers porcine
IL- $\beta-F / R$, IFN- $\beta-F / R$ and actin-F/R (Table 1 ), and the $2^{-\Delta \Delta \mathrm{Ct}}$ method was used to calculate relative expression changes. PCR was performed with PrimeSTAR ${ }^{\circledR} \mathrm{HS}$ DNA Polymerase (R010A, TaKaRa) and the primers LucF/R, PRV US6/7-F/R and PRV US8/9-F/R (Table 1) for the Luc gene and PRV US6/7 and PRV US8/9 genes.

\section{Western blotting}

To examine the expression of viral proteins and firefly luciferase protein, we infected PK-15 and ST cells with rPRV HN1201-EGFP-luc or PRV HN1201 at a multiplicity of infection (MOI) of 0.1 for $24 \mathrm{~h}$. Cells were collected in lysis buffer (50 mM Tris- $\mathrm{HCl}, \mathrm{pH} 8.0,150 \mathrm{mM}$ $\mathrm{NaCl}, 1 \%$ Triton X-100, $1 \%$ sodium deoxycholate, $0.1 \%$ SDS and $2 \mathrm{mM} \mathrm{MgCl}_{2}$ ) supplemented with protease and phosphatase inhibitor cocktail (HY-K0010 and HY-K0022, MedChemExpress). The protein concentrations in the lysates were quantified with a BCA Protein Assay Kit (DingGuo, Beijing, China) and detected with a microplate reader (Awareness Technology, Inc., Palm City, FL, USA). Protein samples $(30 \mu \mathrm{g})$ were separated by SDS-PAGE and transferred to nitrocellulose membranes (ISEQ00010, Millipore), which were incubated in 5\% nonfat milk (A600669, Sangon) for $1 \mathrm{~h}$ at room temperature. The membrane was incubated with antifirefly luciferase antibody (1:3000) (ab185924, Abcam), rabbit antiserum against PRV gE (1:500) (generated by immunizing a rabbit with purified recombinant $g E$ ), antiPRV gB mouse monoclonal antibody (1:2000) (prepared and stored by our laboratory) or anti- $\beta$-actin antibody (1:5000) (A1978, Sigma-Aldrich) at $4{ }^{\circ} \mathrm{C}$ overnight and then incubated with horseradish peroxidase (HRP)-conjugated secondary antibody (715-035-150 or 711-035152, Jackson ImmunoResearch Laboratories) for $1 \mathrm{~h}$. Immunoblotting results were visualized with Luminata Crescendo Western HRP Substrate (WBLUR0500, Millipore) on a GE AI600 imaging system.

\section{Firefly luciferase assay}

The luciferase assay was performed with a Dual-Luciferase ${ }^{\circledR}$ Reporter Assay System (E1960, Promega) according to the manufacturer's instructions. Briefly, growth medium was removed from the cultured cells in a 12-well culture plate, and a sufficient volume of $1 \times$ phosphatebuffered saline (PBS) was gently applied to rinse the bottom of the culture vessel. After $250 \mu \mathrm{L}$ of $1 \times$ Passive Lysis Buffer (PLB) was added to the wells, the plate was shaken gently at room temperature for $15 \mathrm{~min}$, and the cell lysate was transferred to a white 96-well test plate containing $100 \mu \mathrm{L}$ of Luciferase Assay Reagent II (LAR II). The relative light units (RLU) were detected with a Thermo Scientific Fluoroskan Ascent FL (Thermo Fisher, USA). 


\section{Flow cytometry assay}

For the EGFP reporter assay, PK-15 cells were pretreated with $25-\mathrm{HC}$ at the indicated concentration for $4 \mathrm{~h}$ and then infected with rPRV HN1201-EGFP-Luc $(\mathrm{MOI}=0.01)$ and simultaneously treated with $25-\mathrm{HC}$ at the indicated concentration for $18 \mathrm{~h}$. Cells were digested with trypsin-EDTA (25200072, Gibco), collected by centrifugation and suspended in $1 \times$ PBS. The percentage of EGFP-positive cells was measured by flow cytometry on a CytoFLEX instrument.

\section{Assessment of genetic stability}

The rPRV HN1201-EGFP-Luc vector was propagated in PK-15 cells. PK-15 cells at $90 \%$ confluence grown in $10 \mathrm{~cm}$ dishes were infected with rPRV HN1201-EGFPLuc $(\mathrm{MOI}=0.01)$ per cell. After incubation at $37{ }^{\circ} \mathrm{C}$ for $1 \mathrm{~h}$, the cells were washed, and fresh $2 \%(\mathrm{v} / \mathrm{v})$ foetal bovine serum medium was added. When CPEs appeared in most cells, the viruses were harvested and titrated to determine the $\mathrm{TCID}_{50}$ values. To test the genetic stability of rPRV HN1201-EGFP-Luc, we serially passaged the virus in PK-15 cells 20 times, denoted P1 to P20.

\section{Plaque assays}

Plaque assays were performed by infecting confluent PK-15 cells in six-well plates with the indicated viruses. The cells were washed three times with $1 \times \mathrm{PBS}$ and infected with an appropriate dilution of PRV HN1201 or rPRV HN1201-EGFP-Luc containing the same gene copy number for $1 \mathrm{~h}$ at $37{ }^{\circ} \mathrm{C}$ and $5 \% \mathrm{CO}_{2}$. The viral inoculum was removed, and the cells were washed with $1 \times \mathrm{PBS}$ three times. Then, the cell monolayers were overlaid with DMEM (Gibco, Grand Island, NY, USA) containing 1\% methylcellulose (M8070, Solarbio) and 2\% FBS (10099$141 \mathrm{C}$, Gibco) at $37{ }^{\circ} \mathrm{C}$ and $5 \% \mathrm{CO}_{2}$ for $36 \mathrm{~h}$. Next, the medium was removed, and the cell monolayer was fixed with 4\% paraformaldehyde (P1110, Solarbio) for $1 \mathrm{~h}$ and stained with $1 \%$ crystal violet (C8470, Solarbio); plaques were then counted. The number of rPRV HN1201-EGFPLuc plaques was normalized to the number of PRV HN1201 plaques to detect the effect of gI/gE gene knockout on PRV packaging. The plaque diameters were measured from scanned images by using ImageJ.

\section{Mouse survival study}

Mice were used to evaluate the virulence of the recombinant virus rPRV HN1201-EGFP-Luc and the parental strain PRV HN1201. Forty 6-week-old healthy female $\mathrm{BALB} / \mathrm{c}$ mice were randomly divided into five groups of eight. The mice $(n=8)$ in groups $1-4$ were inoculated intramuscularly (I.M.) in the left leg with $10^{2.5} \mathrm{TCID}_{50}$ and $10^{6.5}$ TCID $_{50}$ rPRV HN1201-EGFP-Luc or $10^{2.5}$ $\mathrm{TCID}_{50}$ and $10^{6.5} \mathrm{TCID}_{50}$ PRV HN1201. The mice in group 5 were inoculated with DMEM as an uninfected control. After inoculation, the survival of the mice was recorded every day for 8 days.

\section{Viral infection and in vivo imaging}

For in vivo rPRV HN1201-EGFP-Luc infection, 6-weekold mice (five mice per group) were anaesthetized with isoflurane and inoculated I.M. with rPRV HN1201EGFP-Luc $\left(10^{6.5}, 10^{5.5}, 10^{4.5}, 10^{3.5}\right.$ or $10^{2.5}$ TCID $_{50}$ per mouse). Mice $(n=5)$ inoculated with 2\% FBS DMEM served as an uninfected control. The rPRV HN1201EGFP-Luc distribution in mice was measured by whole body imaging with an IVIS Lumina III (Perkin Elmer) instrument after intraperitoneal injection of D-luciferin sodium salt (HY-12591, MCE) (3 mg per mouse) at the indicated times.

\section{The $25-\mathrm{HC}$ antiviral tests in vivo and in vitro}

PK-15 cells were seeded in 12-well plates $\left(2 \times 10^{5}\right.$ cells/ well) and incubated at $37{ }^{\circ} \mathrm{C}$ with $5 \% \mathrm{CO}_{2}$ for $12 \mathrm{~h}$. PK-15 cells were infected with rPRV HN1201-EGFP-Luc $(\mathrm{MOI}=0.01)$ per cell and $25-\mathrm{HC}$ at the corresponding concentration for $18 \mathrm{~h}$ after pretreatment with $25-\mathrm{HC}$ (HY-113134, MCE) $(0.1 \mu \mathrm{M}, 0.3 \mu \mathrm{M}, 1 \mu \mathrm{M}, 3 \mu \mathrm{M}$ or $10 \mu \mathrm{M})$ for $4 \mathrm{~h}$. DMSO solvent-only control was used in the DMSO group $(1 \mu \mathrm{L}$ of DMSO was added to $1000 \mu \mathrm{L}$ of cell culture medium). The inhibitory effects of $25-\mathrm{HC}$ on PRV proliferation in PK-15 cells were evaluated with firefly luciferase assays, flow cytometry assays and fluorescence analysis.

Six-week-old mice were randomly divided into a $25-\mathrm{HC}$ group and DMSO group (three mice per group). For the $25-\mathrm{HC}$ group, $25-\mathrm{HC}(10 \mathrm{mg} / \mathrm{kg})$ was administered to mice by intraperitoneal injection for 2 consecutive days (once per day). For the DMSO group, mice received the same volume of DMSO. Twelve hours after the last injection of $25-\mathrm{HC}$, all mice were injected I.M. in the left leg with rPRV HN1201-EGFP-Luc $\left(1 \times 10^{4.5}\right.$ TCID $_{50}$ per mouse). The rPRV HN1201-EGFP-Luc distributions in mice were measured with whole animal bioluminescence imaging by using an IVIS Lumina III (Perkin Elmer) instrument after intraperitoneal injection of D-luciferin sodium salt (HY-12591, MCE) (3 mg per mouse) at $24 \mathrm{~h}$ after viral infection.

To determine the suitability of $25-\mathrm{HC}$ as a curative agent, we administered $25-\mathrm{HC}$ after infection. In the experimental animal groups, the injection dosage and methods for $25-\mathrm{HC}$ and DMSO were the same as above, except that each mouse was first infected with $1 \times 10^{4.5}$ TCID $_{50}$ rPRV HN1201-EGFP-Luc and then injected with $25-\mathrm{HC}$ or DMSO $6 \mathrm{~h}$ and $12 \mathrm{~h}$ after virus infection. The rPRV HN1201-EGFP-Luc distributions in mice were measured with whole animal bioluminescence imaging 
$24 \mathrm{~h}$ after viral infection by using an IVIS Lumina III (Perkin Elmer) instrument after intraperitoneal injection of D-luciferin sodium salt (HY-12591, MCE) (3 mg per mouse).

\section{Statistical analysis}

Data were obtained from at least three independent experiments for the quantitative analyses and are expressed as the mean \pm standard errors of the means. All statistical analyses were performed with a $t$-test or one-way analysis of variance. Significant differences were accepted at $P$ values of $<0.05,<0.01$ and $<0.001$ versus the corresponding controls. For mouse survival studies, Kaplan-Meier survival curves were generated and analysed for statistical significance.

\section{Results}

\section{Generation of rPRV HN1201-EGFP-Luc}

PRV glycoprotein I (gI) and glycoprotein E (gE), two adjacent proteins, are nonessential for PRV replication in vitro $[10,37]$. Hence, this region was chosen for insertion of the EGFP and firefly luciferase reporter genes. First, a two sgRNA CRISPR/Cas9 plasmid system (Figure 1A) was constructed to improve the efficiency of PRV genome editing. Subsequently, a donor plasmid containing both EGFP and firefly luciferase expression cassettes flanked by homologous arms was constructed, in which the EGFP expression cassette was under the control of the CAG promoter (a synthetic promoter composed of a CMV enhancer and chicken $\beta$-actin promoter), and the firefly luciferase expression cassette was under the control of the SV40 promoter (Figure 1B). Next, the recombinant virus rPRV HN1201-EGFP-Luc (Figure 1C) was generated by cotransfection of the donor plasmid pUC57-US6/7-EGFP-Luc-US8/9, plasmid PX459MsgRNA1-sgRNA2 and genomic DNA of the parental strain PRV HN1201 into PK-15 cells. Approximately $48 \mathrm{~h}$ post-infection (hpi), clear CPEs were observed, and recombinant viruses were collected and purified with endpoint dilution assays under a fluorescence microscope until all clones showed green fluorescence (Figure 2A). Further DNA sequencing analysis revealed that the viral genomes were cleaved at two sgRNA target sites and repaired by the homology-directed repair (HDR) pathway, thus resulting in a 2459 bp DNA fragment with the PRV gI and gE genes deleted and cassettes containing EGFP and firefly luciferase genes (4198 bp) inserted at the DNA deletion sites (Figure 2B).

\section{Cidentification of the reombinant virus rPRV HN1201-EGFP-Luc}

To confirm the expression of firefly luciferase in PK-15 cells, we extracted total RNA from the cells infected with
rPRV HN1201-EGFP-Luc after $12 \mathrm{~h}$ and performed RTPCR analysis for the presence of firefly luciferase mRNA. The predicted RT-PCR product was $1.6 \mathrm{~kb}$ in size for the firefly luciferase gene in PK-15 cells infected with rPRV HN1201-EGFP-Luc, as confirmed by gel electrophoresis (Figure 2C). No specific bands of similar size were found in any of the mRNA samples of PRV HN1201 or PK-15 cells. As shown in Figure 2D, the gE protein was detected by Western blotting in extracts of PK-15 and ST cells infected with PRV HN1201, whereas no gE protein was expressed in the cells with rPRV HN1201-EGFP-Luc. However, firefly luciferase protein was detected in the PK-15 and ST cells infected with rPRV HN1201-EGFPLuc. The results indicated the deletion of the gE gene and the presence of the firefly luciferase gene in rPRV HN1201-EGFP-Luc. In addition, gB protein expression was observed in the PK-15 and ST cells infected with both rPRV HN1201-EGFP-Luc and PRV HN1201. Firefly luciferase expression in the PK-15 cells infected with rPRV HN1201-EGFP-Luc was also corroborated by determination of firefly luciferase activity (Figure 2E).

\section{Biological characteristics of rPRV HN1201-EGFP-Luc}

To determine whether the deletion of PRV gI/gE and the expression of EGFP and firefly luciferase influenced biological characteristics such as replication capability, lethality to mice and the ability of PRV HN1201 to stimulate cells to produce IL- $1 \beta$ and IFN- $\beta$, we performed one-step growth curves in virus tests, mouse survival tests and RT-qPCR. As shown in Figure 3A, the one-step growth curve of rPRV HN1201-EGFP-Luc was analogous to that of PRV HN1201 in PK-15 cells at early times, whereas the replication of rPRV HN1201-EGFPLuc was slightly slower than that of PRV HN1201 at 24 hpi. The mouse survival test showed that the lethality of rPRV HN1201-EGFP-Luc to mice was comparable to that of PRV HN1201 (Figure 3B). RT-qPCR analysis indicated that the levels of IL- $\beta$ in the 3D4/21 cells stimulated by rPRV HN1201-EGFP-Luc were similar to those in the cells stimulated by PRV HN1201 (Figure 3C). However, a significant $(P<0.05)$ increase in IFN- $\beta$ expression was detected in the $3 \mathrm{D} 4 / 21$ cells stimulated by rPRV HN1201-EGFP-Luc at $12 \mathrm{~h}$ compared with the 3D4/21 cells stimulated by PRV HN1201. A previous study showed that PRV gE/gI is important in suppressing type I interferon in pig plasmacytoid dendritic cells (pDCs) [38]. Our study suggested that the biological characteristics of rPRV HN1201-EGFP-Luc were similar to those of PRV HN1201. However, some differences in the natural hosts (pigs) are worthy of future exploration. The viral titre and luciferase activity from rPRV HN1201-EGFPLuc were stable through at least 20 passages (Figures $3 \mathrm{E}$ 


\section{A}

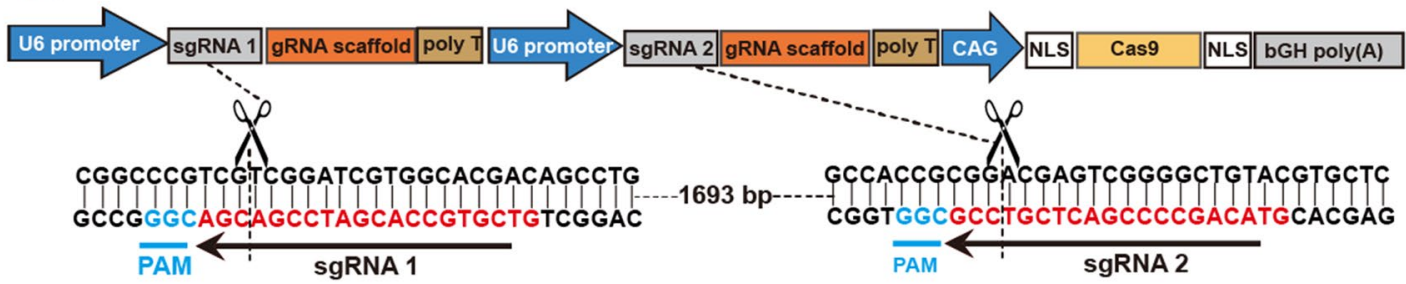

B

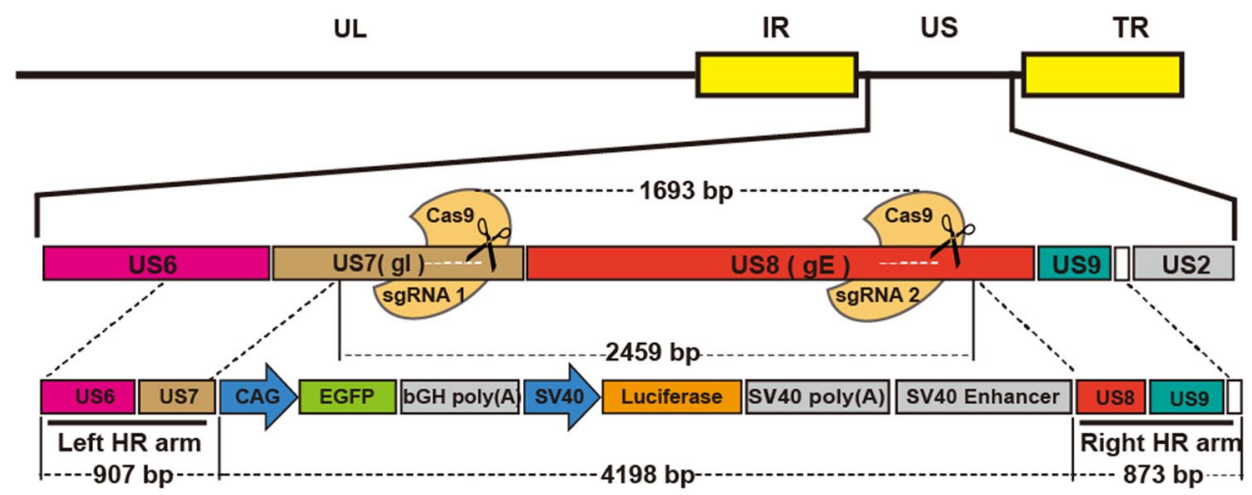

Donor plasmid pUC57-US6/7-EGFP-Luc-US8/9

C

pX459M-sgRNA1-sgRNA2+PRV genome+Donor plasmid

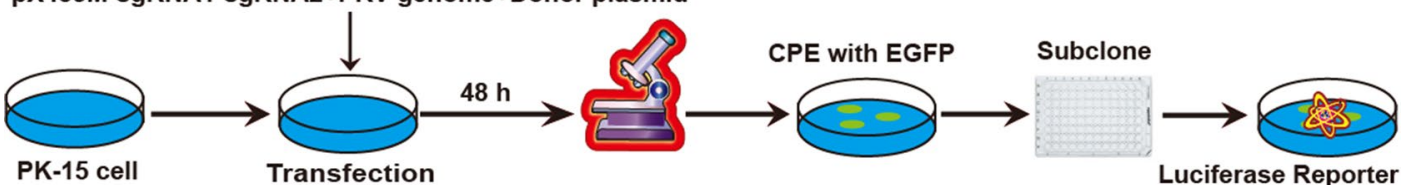

PCR and sequencing DNA extraction

Figure 1 The double-sgRNA CRISPR/Cas9 system and the protocol used to generate the recombinant virus rPRV HN1201-EGFP-Luc. A Schematic diagrams of the double -sgRNA CRISPR/Cas9 system and the CRISPR/Cas9 cleavage positions. B Diagrams showing the PRV HN1201 genome and the donor plasmid. In the donor plasmid, the left homologous recombination arm (left HR arm) and the right HR arm are located upstream and downstream of the sgRNA1 and sgRNA2 target sites, respectively. There were 1693 base pairs (bp) between the two sgRNA target sites. After the PRV genome is cut at the two sgRNA target sites and homologous recombination occurs, the PRV genome loses a 2459 bp DNA fragment, and the cassette containing the EGFP and luciferase genes is knocked in at the DNA deletion sites. C Diagram depicting the protocol used to obtain and purify recombinant PRV for the expression of EGFP and luciferase genes. A mixture of PRV HN1201 genomes, Cas9/sgRNAs and donor plasmid was cotransfected into PK-15 cells. CPEs with EGFP were observed 2-4 days after transfection. Cells and media were collected after three freeze-thaw cycles and then inoculated into cells in 96-well plates after serial dilutions to obtain single viral clones. Subcloned viruses were subjected to luciferase assays and sequence analysis.

and F), thus indicating that rPRV HN1201-EGFP-Luc was stable.

To further investigate the effect of gI/gE gene deletion on the biological characteristics of PRV HN1201, we performed plaque assays standardized by PRV genome copy numbers to determine the number and diameter of plaques of PRV HN1201 and rPRV
HN1201-EGFP-Luc. As shown in Figure 3G, the number of plaques formed by PRV HN1201 and rPRV HN1201-EGFP-Luc in PK-15 cells was not significantly different. However, the recombinant virus rPRV HN1201-EGFP-Luc formed smaller plaques than the wild-type virus PRV HN1201 (Figure 3H). These results suggested that loss of $\mathrm{gI} / \mathrm{gE}$ had no significant 


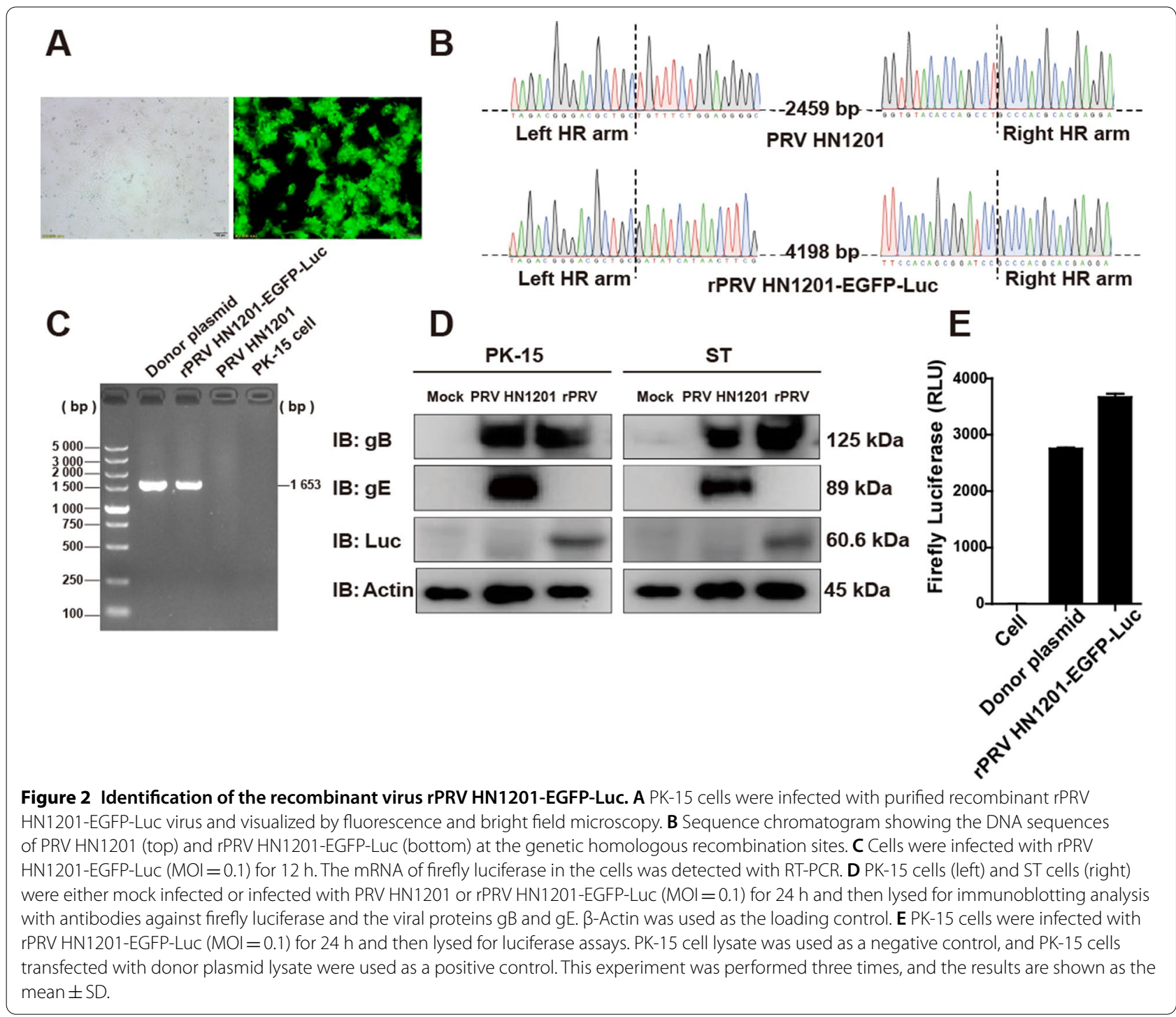

effect on PRV particle assembly but diminished the spread of PRV between cells. Several previous studies also support this conclusion $[39,40]$.

\section{Viral titre, EGFP and luciferase activity of the recombinant virus}

To assay the viral titre, EGFP signal and firefly luciferase activity of rPRV HN1201-EGFP-Luc could be used to evaluate the proliferation of the virus. PK-15 cells were infected with rPRV HN1201-EGFP-Luc $(\mathrm{MOI}=0.001,0.01,0.1$ and 1$)$, and the EGFP signal, viral titre and luciferase activity of the virus were detected at certain time points. Western blotting and fluorescence microscopy observations showed that the signal for $\mathrm{gB}$ and the number of viral plaques increased with increasing viral infection in cells (Figures 4A and B). Combined with the results of flow cytometry assays (Figure $4 \mathrm{C}$ ), luciferase activity (Figure $4 \mathrm{D}$ ) and $\mathrm{TCID}_{50}$ (Figure 4E), further analysis showed that the viral titre and EGFP of the recombinant virus linearly correlated with the luciferase activity (Figures $4 \mathrm{~F}$ and $4 \mathrm{G}$ ). Therefore, the viral titre, EGFP signal or firefly luciferase activity of recombinant virus could be used to evaluate the replication of recombinant virus.

\section{In vivo tracing and distribution of recombinant virus in mice}

In mice infected with $10^{4.5}, 10^{5.5}$ or $10^{6.5} \mathrm{TCID}_{50}$ recombinant virus, bioluminescence signals were detected at the injection site at $12 \mathrm{~h}$ and were detected at the injection site and spine at $24 \mathrm{~h}$ (Figure 5). Weak bioluminescence 
signals were detected in the mice infected with $10^{3.5}$ $\mathrm{TCID}_{50}$ recombinant virus at the injection site at $48 \mathrm{hpi}$ (Figure 5). At $72 \mathrm{hpi}$, the bioluminescence signals were found mainly in the spines of the mice infected with $10^{2.5}$ and $10^{3.5} \mathrm{TCID}_{50}$ recombinant virus, indicating that the PRV had transferred from the inoculation site to the spinal cord (Figure 5); these findings were in agreement with the mechanism of PRV infection and distribution. These results showed that the recombinant virus can be used to visualize the replication and distribution of PRV in vivo.

\section{The $25-\mathrm{HC}$ antiviral tests in vivo and in vitro}

The $25-\mathrm{HC}$ compound is an oxidation product of cholesterol whose formation is catalysed by cholesterol25-hydroxylase $(\mathrm{CH} 25 \mathrm{H})$ [41]. This molecule not only functions as a potent oxysterol regulator of lipid metabolism [42] but also has important effects in immunity [43-46]. In a previous study, $25-\mathrm{HC}$ was shown to broadly inhibit viruses, such as vesicular stomatitis virus (VSV), herpes simplex virus (HSV), human immunodeficiency virus (HIV) and murine gamma herpes virus 68 (MHV68) [47]. The inhibitory effect of 25-HC on PRV in vitro has been confirmed in our previous studies [48], but whether it has the same effect on PRV in vivo is unknown. Here, the double reporter PRV was used to confirm the effect of $25-\mathrm{HC}$ on PRV reproduction in PK-15 cells and to further explore the effect of $25-\mathrm{HC}$ on PRV reproduction in mice. The luciferase activity of the PK-15 cells treated with DMSO was significantly higher than that of the PK-15 cells treated with $25-\mathrm{HC}$ $(P<0.001)$, and the luciferase activity of the PK-15 cells treated with 25 -HC decreased in a dose-dependent manner (Figure 6A). As shown in Figure 6B, treatment with 25-HC significantly decreased the EGFP percentage in a dose-dependent manner compared with the percentages in the PK-15 cells treated with DMSO $(P<0.001)$. In addition, the fluorescence intensity in the PK-15 cells treated with $25-\mathrm{HC}$ was weaker (Figure $6 \mathrm{C}$ ). The results suggested that $25-\mathrm{HC}$ inhibited the proliferation of PRV in PK-15 cells in a dose-dependent manner.

In vivo whole-animal bioluminescence imaging of the mice infected with the double reporter PRV was performed, and the 25-HC-treated group showed less bioluminescence than the DMSO group (Figure 6D), thus indicating that $25-\mathrm{HC}$ also inhibited PRV in vivo. However, in a therapeutic experiment in which $25-\mathrm{HC}$ was injected after PRV infection in mice, 25-HC showed a slight inhibition of PRV (Figure 6E), but this anti-PRV effect was not as pronounced as its preventive effect on PRV. Together, these results demonstrated that rPRV HN1201-EGFP-Luc is a useful tool for screening antiviral compounds both in vivo and in vitro.

\section{Discussion}

Viral reverse genetics and the construction of reporter viruses provide a powerful tool for antiviral development and basic virology studies. Red fluorescent protein (RFP) $[49,50]$ and green fluorescent protein (GFP) [51] cassettes are often inserted into the PRV genome as markers, and these reporter viruses have been widely used in the screening of antiviral drugs [52] and in studies of antiviral gene function in vitro [53]. However, the viruses carrying these two markers appear to be unable to be used in antiviral studies in vivo, owing to the limited penetration ability of GFP and RFP. In this study, the recombinant pseudorabies virus rPRV HN1201-EGFP-Luc based on the variant PRV strain PRV HN1201 was developed to express both EGFP and firefly luciferase. The insertion of EGFP and the firefly luciferase expression cassette had no significant effects on viral replication (at early times), lethality to mice or the ability to stimulate 3D4/21 cells to produce IL-1 $\beta$ (Figures $3 \mathrm{~A}-\mathrm{C}$ ). Although the gI and gE genes are nonessential for PRV proliferation, they play a role in the process of PRV infection of cells or animal bodies. For example, the gE/gI complex promotes cellcell spreading and is involved in the release of the virus from cells and in cell fusion in vitro [39]. Moreover, gEnegative PRV showed a substantially diminished ability to infect second- and third-order neurons in the porcine central nervous system (CNS) [54]. The underlying molecular mechanism remains to be further explored. The PRV gene editing strategy and the recombinant virus in this study should enable convenient study of the pathogenic mechanism of PRV. The recombinant virus remained stable even after 20 passages, as confirmed by both viral titre and luciferase activity assays (Figures $3 \mathrm{E}$ and F). Here, we further explored the relationships among viral titre, EGFP and luciferase activity in recombinant virus-infected cells. The viral titre and EGFP of the recombinant virus were linearly correlated with the luciferase activity (Figures 4F and G), thus suggesting that the viral titre, EGFP signal or firefly luciferase activity of the recombinant virus could be used to evaluate the replication of recombinant virus.

In some previous studies, the firefly luciferase expression cassette was recombined into PRV for expression $[55,56]$, but few studies have reported imaging of PRV in vivo. In this study, the imaging characteristics were analysed in vivo in mice infected with different doses of the recombinant virus rPRV HN1201-EGFP-Luc. The bioluminescence signal was detected in mice as early as 12 hpi (Figure 5). Using the reporter virus, we demonstrated that $25-\mathrm{HC}$ inhibited PRV replication both in vivo and in vitro. These results suggested that the reporter viruses constructed in this study may play an important 
A

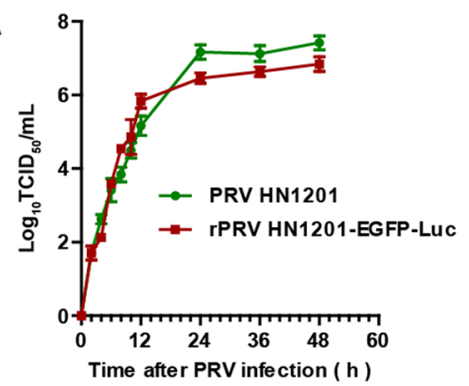

C

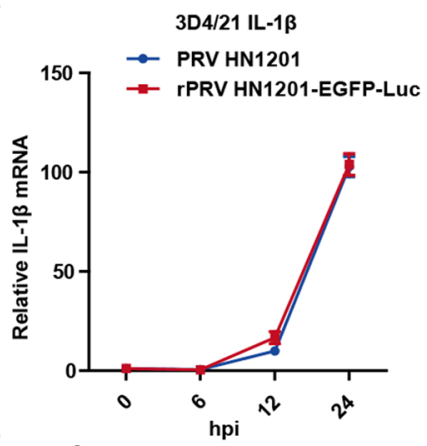

E

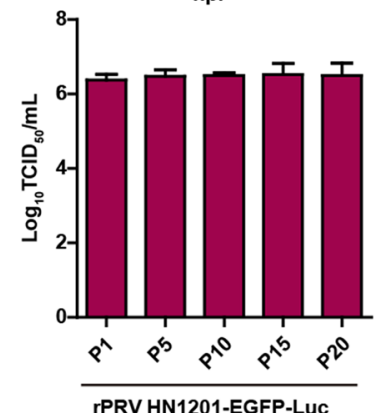

G

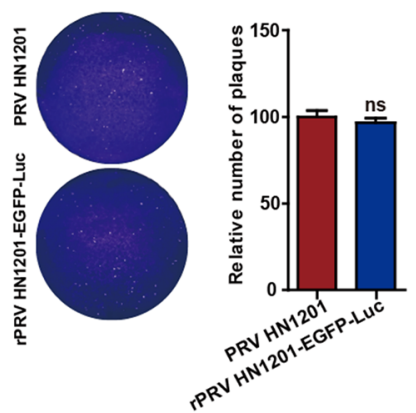

B

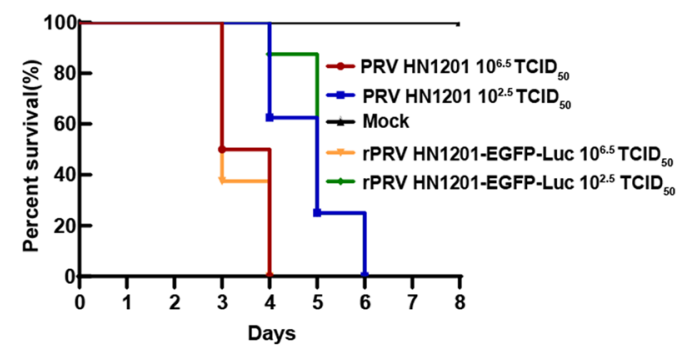

D
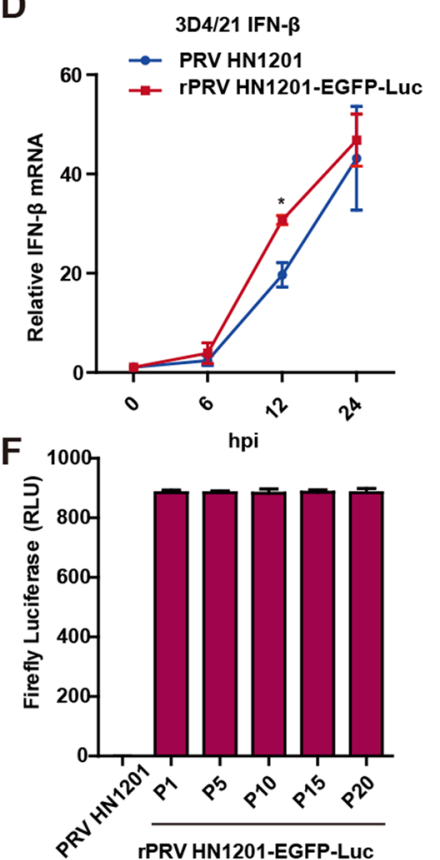

H

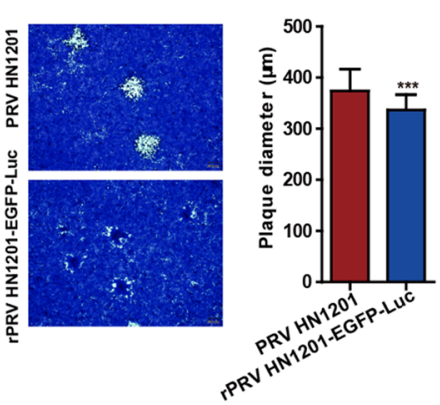

Figure 3 Biological characteristics of the recombinant virus rPRV HN1201-EGFP-Luc. A One-step growth curves of PRV HN1201 (MOI=0.1) and rPRV HN1201-EGFP-Luc (MOI=0.1) in PK-15 cells. This experiment was performed three times, and the results are shown as the mean \pm SD. B Percentage survival of mice (eight mice per group) infected I.M. with $10^{6.5} \mathrm{TCID}_{50}$ and $10^{2.5} \mathrm{TCID}_{50}$ of PRV HN1201 and rPRV HN1201-EGFP-Luc. C, D Equal numbers of 3D4/21 cells were infected with PRV HN1201 or rPRV HN1201-EGFP-Luc at an MOI of 1. Total RNA was collected at 6, 12 and 24 hpi, and then, IL-1 $\beta(\mathbf{C})$ and IFN- $\beta$ (D) mRNA expression was quantified by RT-qPCR. This experiment was performed three times, and the results are shown as the mean \pm SD. E The rPRV HN1201-EGFP-Luc passage experiments were performed in PK-15 cells (passages 1-20), and then, viral titre was determined with $\mathrm{TCID}_{50}$ assays at specific passages $(1,5,10,15$ and 20) of rPRV HN1201-EGFP-Luc. Data are shown as the mean \pm SD from three independent experiments. F PK-15 cells were infected with specific passages $(1,5,10,15$ or 20) of rPRV HN1201-EGFP-Luc (MOI=0.1). Luciferase assays were performed in triplicate at the indicated times after infection. Data are shown as the mean \pm SD from three independent experiments. G The plaque assay standardized on genome copy numbers. The number of rPRV HN1201-EGFP-Luc plaques was normalized to the number of PRV HN1201 plaques to detect the effect of $\mathrm{gl} / \mathrm{gE}$ gene knockout on PRV packaging. Representative data from triplicate experiments are shown. Mean + SD, ns, no significant difference. H Plaque sizes of PK-15 cells infected with PRV HN1201 or rPRV HN1201-EGFP-Luc at 36 hpi. The mean plaque diameter of 50 plaques from one representative experiment out of three independent experiments is shown. Mean $+S D$, ${ }^{* * *} P<0.001$. 


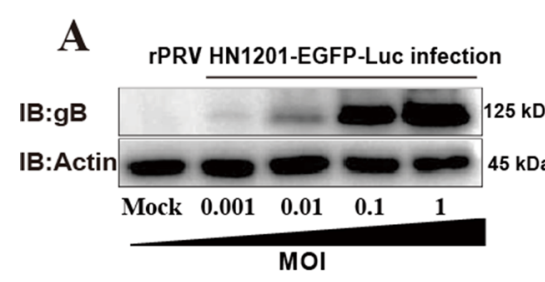

B

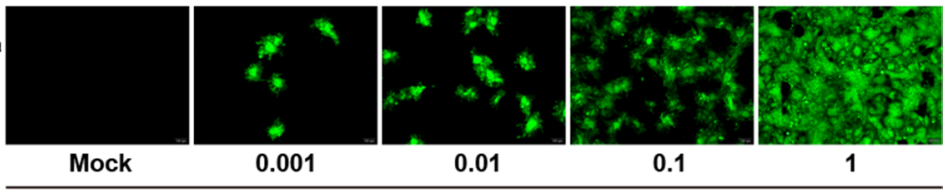

rPRV HN1201-EGFP-Luc (MOI)

C

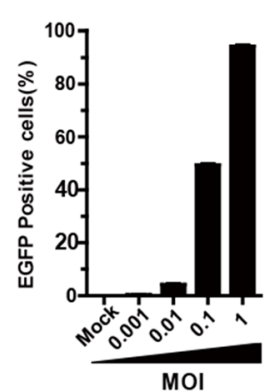

D

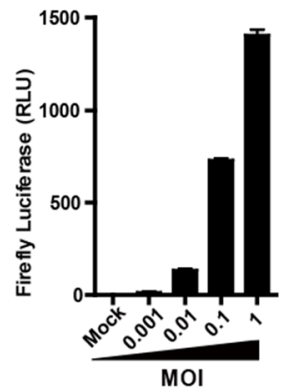

E

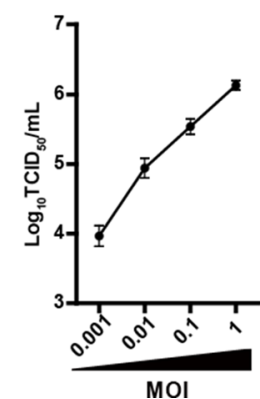

$\mathbf{F}$

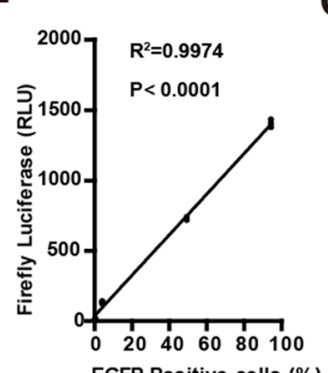

G

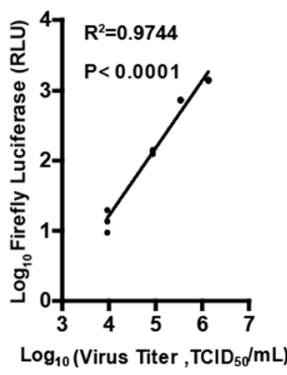

Figure 4 Firefly luciferase activity, GFP expression and viral titre of recombinant virus. A PK-15 cells were infected with rPRV HN1201-EGFP-LUC (MOI=0.001, 0.01, 0.1 or 1$)$ for $18 \mathrm{~h}$ and then lysed for immunoblotting analysis with antibodies against viral protein gB. $\beta$-Actin was used as the loading control. Fluorescence microscopy (B), fluorescence-activated cell sorting (FACS) analysis (C), luciferase assays (D) and TCID ${ }_{50}$ assays (E) of rPRV HN1201-GFP-Luc (MOI $=0.001,0.01,0.1$ or 1$)$ proliferation in PK-15 cells for $18 \mathrm{~h}$. Data are shown as the mean \pm SD from three independent experiments. Scale bar, $100 \mu \mathrm{m}$. F Correlation between luminescence intensity and GFP expression ( ${ }^{2}=0.9974, p<0.0001 ; \mathrm{GraphPad}$ Prism 5, La Jolla, CA, USA). G Correlation between luminescence intensity and infectious viral titres $\left(\mathrm{TCID}_{50}\right)\left(\mathrm{R}^{2}=0.9744, p<0.0001 ; \mathrm{GraphPad}\right.$ Prism 5, La Jolla, CA, USA).

role in studies of PRV mutant strains both in vivo and in vitro.

Compound 25-HC is an oxidation product of cholesterol, whose formation is catalysed by cholesterol-25-hydroxylase $(\mathrm{CH} 25 \mathrm{H})$. Previous studies have shown that 25-HC treatment in cultured cells broadly inhibited the growth of enveloped viruses such as herpes simplex virus (HSV) [47, 57], human immunodeficiency virus (HIV) [47, 58], Ebola virus (EBOV) [59], Nipah virus (NiV) [47] and Rift Valley fever virus (RVFV) [47]. This treatment suppresses viral growth by blocking membrane fusion between the virus and cell. Further research has shown that $25-\mathrm{HC}$ directly modifies the cellular membrane, thereby inhibiting viral fusion [47]. Membrane fusion is critical for host-virus interactions, and several factors, including the viral receptors on the cell surface, the degree of curvature, the spatial conformation of membrane phospholipid bilayers, and the arrangement and mobility of phospholipid molecules, are involved in this step [60, 61]. Another study has shown that 25-HC loosens cholesterol molecules in cytomembranes, thus changing the location, arrangement and solubility of cholesterol in cytomembranes [62]. In our previous research, we demonstrated that $25-\mathrm{HC}$ inhibits PRV infection by blocking the attachment and entry of the virus [48]. In addition, $q P C R$ detection revealed that the levels of the enzymes synthesizing fatty acids (ACC, FAS and SREBP1) and cholesterol (HMGCR, HMGCS and SREBP2) decreased in 3D4/21 cells treated with 25-HC. Diminished sterol synthesis may alter the lipid distribution in the cell membrane. Cellular cholesterol metabolism is important in the viral life cycle, and the depletion of cholesterol in cell membranes prevents the formation of lipid rafts and inhibits PRV entry [63]. On the basis of the literature and our previous research, we speculate that the anti-PRV activity of $25-\mathrm{HC}$ is mainly based on modulation of the biosynthesis of cholesterol or other metabolites, thus further affecting the characteristics of cytomembranes. Nevertheless, the specific molecular mechanism of 25-HC against PRV requires further study.

In previous studies, CRISPR/Cas9 technology has been widely used in viral genome editing [49, 50, 55, 64-67]. Most studies have used a single sgRNA to cleave the viral genome, and the damaged DNA is repaired via errorprone nonhomologous end joining (NHEJ) in cell repair pathways; this approach tends to produce random additions, deletions or synonymous repair at the original site [68]. A recent study used homology-directed repair following CRISPR/Cas9 cleavage to produce recombinant PRV virus [69]. In our study, a two-sgRNA CRISPR/ 


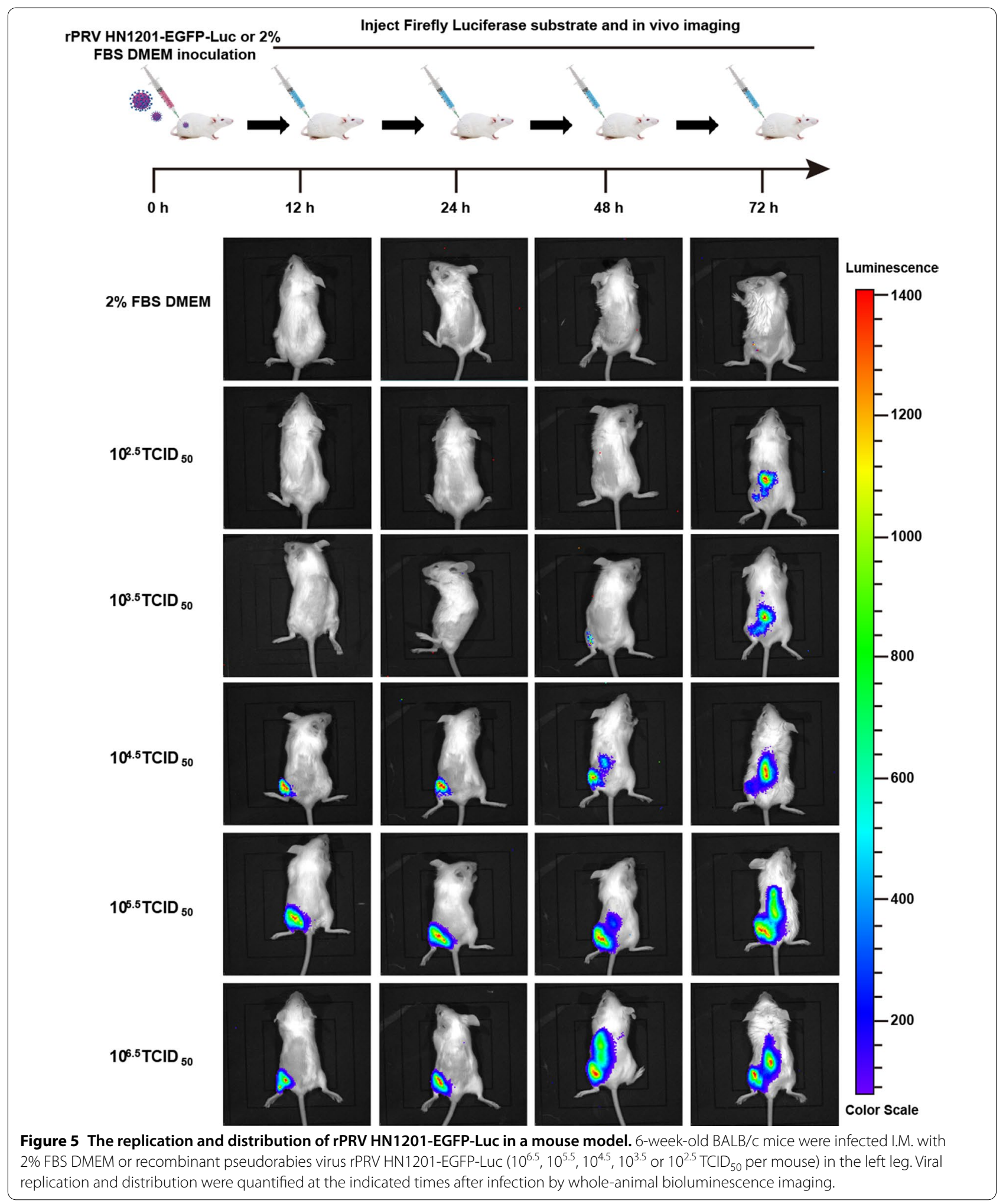



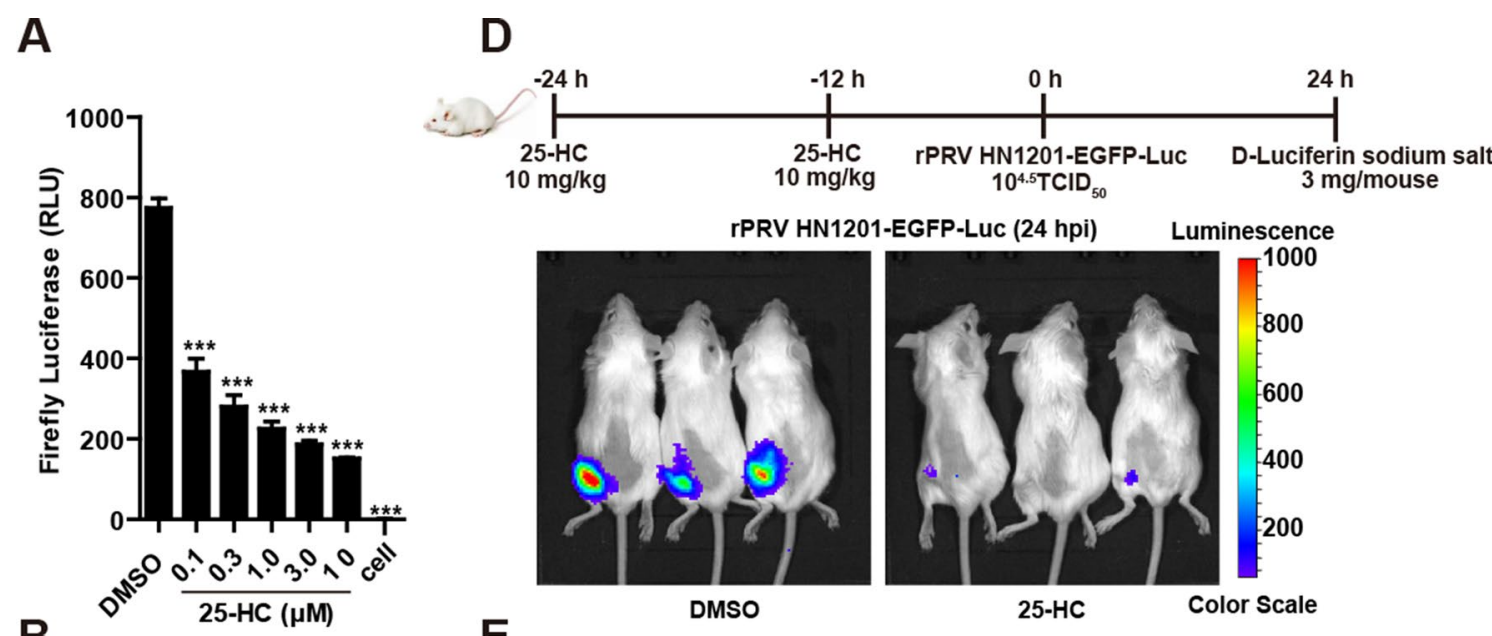

B
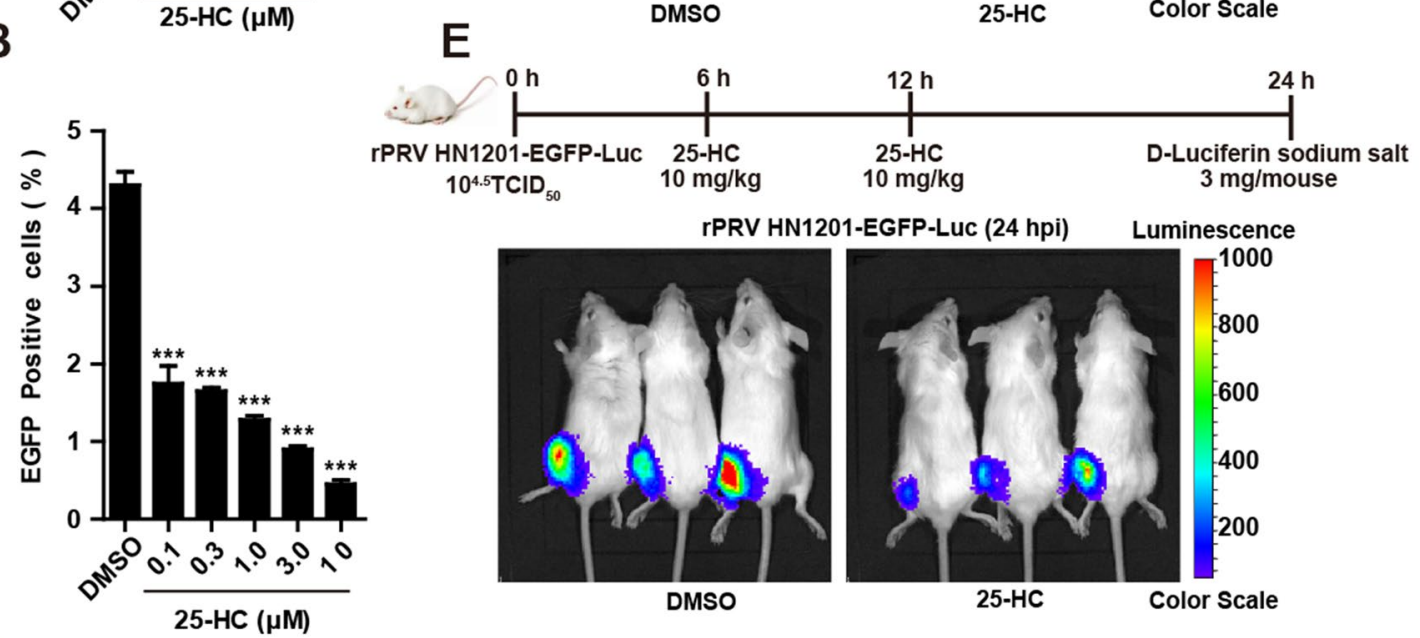

C

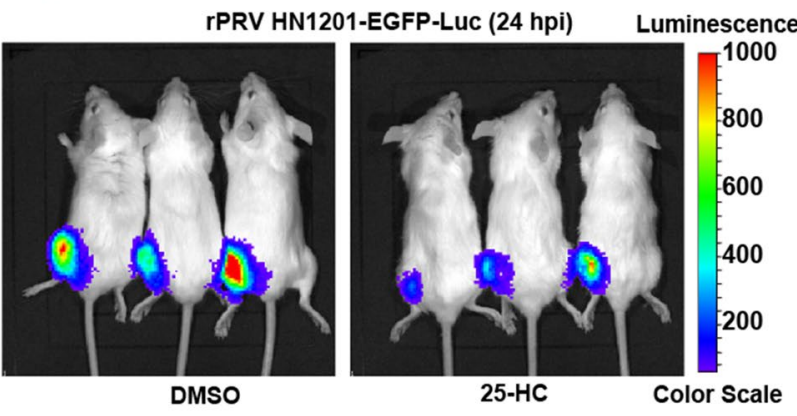

rPRV HN1201-EGFP-LUC (MOI=0.01)

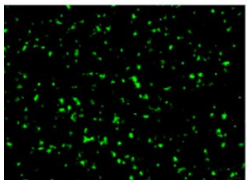

DMSo

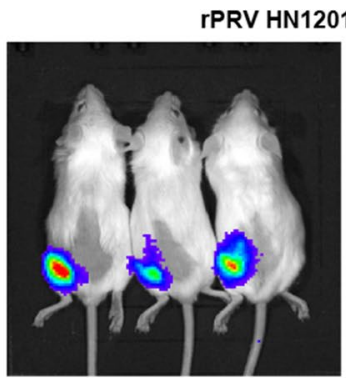

EGFP-Luc (24 hpi) Luminescence
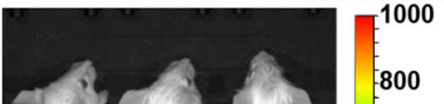

600

400

$-200$

\section{cence}

00

00

200

5-HC Color Scale

PRV HN1201 EGP

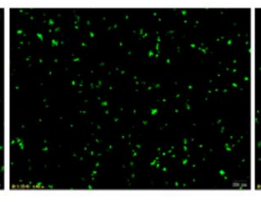

0.1

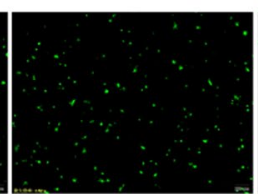

0.3

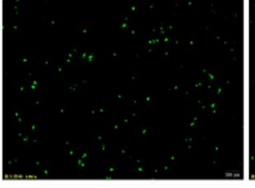

1.0

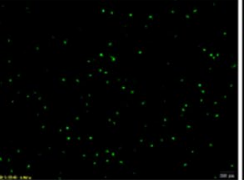

3.0

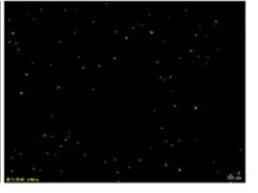

10

25-HC ( $\mu \mathrm{M})$

Figure 6 The 25-HC antiviral tests in vivo and in vitro. Treatment with 25-HC inhibited the proliferation of rPRV HN1201-EGFP-Luc in vitro. PK-15 cells were pretreated with the indicated concentrations of 25-HC for $4 \mathrm{~h}$ and then infected with rPRV HN1201-EGFP-LuC (MOI=0.01) along with the same concentrations of 25- HC for $18 \mathrm{~h}$. Luciferase assays (A), FACS analysis (B) and fluorescence microscopy (C) were performed. Data are shown as the mean \pm SD from three independent experiments. Scale bar, $200 \mu m$. ${ }^{* * *} P<0.001$. D Bioluminescent images of mice pretreated with 25-HC or DMSO at $24 \mathrm{~h}$ after rPRV HN1201-EGFP-Luc infection. E Bioluminescent images of mice in which 25-HC or DMSO was injected later upon rPRV HN1201-EGFP-Luc infection. Whole animal bioluminescence imaging was performed $24 \mathrm{~h}$ after rPRV HN1201-EGFP-Luc infection.

Cas9 system was developed with two sgRNAs targeting the PRV gI and gE genes. To enable the two sgRNAs and Cas9 proteins to edit the viral genome in the same cell, we used the two-sgRNA CRISPR/Cas9 systems constructed in this study in a single plasmid system to cut the specific sites of the gI and gE genes of PRV. Then, the EGFP and firefly luciferase expression cassettes were inserted into the PRV HN1201 genome through intracellular homology-directed repair (HDR). The two sgRNA CRISPR/Cas9 systems constructed herein can be used not only to knock out large DNA fragments of PRV but also to effectively insert other foreign antigens. 
The parental strain PRV HN1201 in this study is a Chinese PRV variant strain that is more pathogenic to pigs than the classic Fa strain [20]. Phylogenetic analysis illustrated that PRV HN1201 is genetically closest to the PRV human isolate hSD-1/2019 described in a recent report [25]. Hence, the reporter virus constructed on the basis of PRV HN1201 may be useful in future research.

In summary, the two-sgRNA CRISPR/Cas9 single plasmid systems used herein provided a good reference method for gene editing of PRV or any other dsDNA virus. A stable replication-competent recombinant pseudorabies virus, rPRV HN1201-EGFP-Luc carrying the EGFP and firefly luciferase expression cassettes, was generated. The reporter virus should be an excellent tool for the study of basic virology and the evaluation of antiviral compounds both in vitro and in vivo.

\begin{abstract}
Abbreviations
PRV: Pseudorabies virus; EGFP: Enhanced green fluorescent protein; PR: Pseudorabies; gE: Glycoprotein E; kb: Kilobases; HR: Homologous recombination; BAC: Bacterial artificial chromosome; CRISPR/Cas9: Clustered regulatory interspaced short palindromic repeats/CRISPR-associated protein 9; 25-HC: 25-Hydroxycholesterol; DMEM: Dulbecco's modified eagle's medium; FBS: Foetal bovine serum; sgRNA1: Small guide RNA1; sgRNA2: Small guide RNA2; CPEs: Cytopathic effects; MOI: Multiplicity of infection; HRP: Horseradish peroxidase; PBS: Phosphate-buffered saline; PLB: Passive lysis buffer; LAR II: Luciferase assay reagent II; RLU: Relative light units; I.M.: Intramuscularly; gl: Glycoprotein l; CAG: CMV enhancer and chicken $\beta$-actin promoter; hpi: Hour post-infection; HDR: Homology-directed repair; pDC: Plasmacytoid dendritic cells; CH25H: Cholesterol-25-hydroxylase; VSV: Vesicular stomatitis virus; HSV: Herpes simplex virus; HIV: Human immunodeficiency virus; MHV68: Murine gamma herpes virus 68; RFP: Red fluorescent protein; GFP: Green fluorescent protein; NHEJ: Nonhomologous end joining; CNS: Central nervous system; EBOV: Ebola virus; NiV: Nipah virus; RVFV: Rift valley fever virus.
\end{abstract}

\section{Acknowledgements}

We thank Professor Hong-Ying Chen of Henan Agricultural University for her help in improving the experimental technology and editing the article.

\section{Authors' contributions}

Writing review and supervision: PF; data curation, writing original draft: XC; formal analysis, software: BS; visualization: LD; investigation: CW and $\mathrm{XrN}$; resources: JW; project administration, supervision: GY; funding acquisition, supervision, writing — review and editing: BC. All authors have read and approved the final manuscript.

\section{Funding}

This work was supported by grants from the Training Plan of Young Key Teachers in Colleges and Universities of Henan Province (2016GGJS-033) and the Natural Science Foundation of Henan (202300410213).

\section{Availability of data and materials}

All data and materials generated for this study are included in the article.

\section{Declarations}

\section{Ethics approval and consent to participate}

The Animal Care Committee of Henan Agricultural University (Zhengzhou, People's Republic of China) approved this study (approval number 11-0085), and all animals were maintained in a specific pathogen-free animal facility according to the related ethical regulations at Henan Agricultural University and the guide for the care and use of laboratory animals.

\section{Competing interests}

The authors declare that they have no competing interests.

Received: 19 January 2021 Accepted: 27 May 2021

Published online: 26 June 2021

\section{References}

1. Mettenleiter TC (1996) Immunobiology of pseudorabies (Aujeszky's disease). Vet Immunol Immunopathol 54:221-229

2. Klupp BG, Hengartner CJ, Mettenleiter TC, Enquist LW (2004) Complete, annotated sequence of the pseudorabies virus genome. J Virol 78:424-440

3. Mettenleiter TC (2000) Aujeszky's disease (pseudorabies) virus: the virus and molecular pathogenesis — state of the art, June 1999. Vet Res 31:99-115

4. Koyuncu OO, Hogue IB, Enquist LW (2013) Virus infections in the nervous system. Cell Host Microbe 13:379-393

5. Qi H, Wu H, Abid M, Qiu HJ, Sun Y (2020) Establishment of a fosmid library for pseudorabies virus SC strain and application in viral neuronal tracing. Front Microbiol 11:1168

6. Lee JY, Wilson MR (1979) A review of pseudorabies (Aujeszky's disease) in pigs. Can Vet J 20:65-69

7. Freuling CM, Muller TF, Mettenleiter TC (2017) Vaccines against pseudorabies virus (PrV). Vet Microbiol 206:3-9

8. Baskerville A, Lloyd G (1977) Experimental infection of monkeys with herpesvirus suis (Aujeszky's-disease virus). J Med Microbiol 10:139-144

9. Hurst EW (1936) Studies on pseudorabies (infectious bulbar paralysis, mad itch): lii. The disease in the rhesus monkey, Macaca Mulatta. J Exp Med 63:449-463

10. Pomeranz LE, Reynolds AE, Hengartner CJ (2005) Molecular biology of pseudorabies virus: impact on neurovirology and veterinary medicine. Microbiol Mol Biol Rev 69:462-500

11. Laval K, Vernejoul JB, Van Cleemput J, Koyuncu OO, Enquist LW (2018) Virulent pseudorabies virus infection induces a specific and lethal systemic inflammatory response in mice. J Virol 92:e01614-e1618

12. Ren J, Wang H, Zhou L, Ge X, Guo X, Han J, Yang H (2020) Glycoproteins C and D of PRV strain HB1201 contribute individually to the escape from Bartha-K61 vaccine-induced immunity. Front Microbiol 11:323

13. An TQ, Peng JM, Tian ZJ, Zhao HY, Li N, Liu YM, Chen JZ, Leng CL, Sun Y, Chang D, Tong GZ (2013) Pseudorabies virus variant in Bartha-K61-vaccinated pigs, China, 2012. Emerg Infect Dis 19:1749-1755

14. Yu X, Zhou Z, Hu D, Zhang Q, Han T, Li X, Gu X, Yuan L, Zhang S, Wang B, Qu P, Liu J, Zhai X, Tian K (2014) Pathogenic pseudorabies virus, China, 2012. Emerg Infect Dis 20:102-104

15. Ye C, Zhang QZ, Tian ZJ, Zheng H, Zhao K, Liu F, Guo JC, Tong W, Jiang CG, Wang SJ, Shi M, Chang XB, Jiang YF, Peng JM, Zhou YJ, Tang YD, Sun MX, Cai XH, An TQ, Tong GZ (2015) Genomic characterization of emergent pseudorabies virus in China reveals marked sequence divergence: evidence for the existence of two major genotypes. Virology 483:32-43

16. Xiang S, Zhou Z, Hu X, Li Y, Zhang C, Wang J, Li X, Tan F, Tian K (2016) Complete genome sequence of a variant pseudorabies virus strain isolated in central China. Genome Announc 4:e00149-e216

17. Luo Y, Li N, Cong X, Wang CH, Du M, Li L, Zhao B, Yuan J, Liu DD, Li S, Li Y, Sun Y, Qiu HJ (2014) Pathogenicity and genomic characterization of a pseudorabies virus variant isolated from Bartha-K61-vaccinated swine population in China. Vet Microbiol 174:107-115

18. Gu Z, Hou C, Sun H, Yang W, Dong J, Bai J, Jiang P (2015) Emergence of highly virulent pseudorabies virus in southern China. Can JVet Res 79:221-228

19. Ye C, Guo JC, Gao JC, Wang TY, Zhao K, Chang XB, Wang Q, Peng JM, Tian ZJ, Cai XH, Tong GZ, An TQ (2016) Genomic analyses reveal that partial sequence of an earlier pseudorabies virus in China is originated from a Bartha-vaccine-like strain. Virology 491:56-63

20. Yang QY, Sun Z, Tan FF, Guo LH, Wang YZ, Wang J, Wang ZY, Wang LL, Li XD, Xiao Y, Tian KG (2016) Pathogenicity of a currently circulating Chinese variant pseudorabies virus in pigs. World J Virol 5:23-30

21. Ai JW, Weng SS, Cheng Q, Cui P, Li YJ, Wu HL, Zhu YM, Xu B, Zhang WH (2018) Human endophthalmitis caused by pseudorabies virus infection, China, 2017. Emerg Infect Dis 24:1087-1090 
22. Fan S, Yuan H, Liu L, Li H, Wang S, Zhao W, Wu Y, Wang P, Hu Y, Han J, Lyu Y, Zhang W, Chen P, Wu H, Gong Y, Ma Z, Li Y, Yu J, Qiao X, Li G, Zhao Y, Wang D, Ren H, Peng B, Cui L, Wang J, Guan H (2020) Pseudorabies virus encephalitis in humans: a case series study. J Neurovirol 26:556-564

23. Tischer BK, Osterrieder N (2010) Herpesviruses-a zoonotic threat? Vet Microbiol 140:266-270

24. Zhao WL, Wu YH, Li HF, Li SY, Fan SY, Wu HL, Li YJ, Lu YL, Han J, Zhang WC, Zhao Y, Li GL, Qiao XD, Ren HT, Zhu YC, Peng B, Cui LY, Guan HZ (2018) Clinical experience and next-generation sequencing analysis of encephalitis caused by pseudorabies virus. Zhonghua Yi Xue Za Zhi 98:1152-1157

25. Liu Q, Wang X, Xie C, Ding S, Yang H, Guo S, Li J, Qin L, Ban F, Wang D, Wang C, Feng L, Ma H, Wu B, Zhang L, Dong C, Xing L, Zhang J, Chen H, Yan R, Wang X, Li W (2020) A novel human acute encephalitis caused by pseudorabies virus variant strain. Clin Infect Dis. https://doi.org/10.1093/ $\mathrm{cid} / \mathrm{cia} 9987$

26. Zhao Y, Wang LQ, Zheng HH, Yang YR, Liu F, Zheng LL, Jin Y, Chen HY (2020) Construction and immunogenicity of a gE/gl/TK-deleted PRV based on porcine pseudorabies virus variant. Mol Cell Probes 53:101605

27. Yin H, Li Z, Zhang J, Huang J, Kang H, Tian J, Qu L (2020) Construction of a US7/US8/UL23/US3-deleted recombinant pseudorabies virus and evaluation of its pathogenicity in dogs. Vet Microbiol 240:108543

28. Zheng HH, Wang LQ, Fu PF, Zheng LL, Chen HY, Liu F (2020) Characterization of a recombinant pseudorabies virus expressing porcine parvovirus VP2 protein and porcine IL-6. Virol J 17:19

29. Tian ZJ, Zhou GH, Zheng BL, Qiu HJ, Ni JQ, Yang HL, Yin XN, Hu SP, Tong GZ (2006) A recombinant pseudorabies virus encoding the HA gene from H3N2 subtype swine influenza virus protects mice from virulent challenge. Vet Immunol Immunopathol 111:211-218

30. Olsen LM, Ch'ng TH, Card JP, Enquist LW, (2006) Role of pseudorabies virus Us3 protein kinase during neuronal infection. J Virol 80:6387-6398

31. Zhang C, Liu Y, Chen S, Qiao Y, Guo M, Zheng Y, Xu M, Wang Z, Hou J, Wang J (2019) A gD\&gC-substituted pseudorabies virus vaccine strain provides complete clinical protection and is helpful to prevent virus shedding against challenge by a Chinese pseudorabies variant. BMC Vet Res 15:2

32. Wang T, Tong W, Ye C, Yu Z, Chen J, Gao F, Shan T, Yu H, Li L, Li G, Tong $G$, Zheng $H$ (2018) Construction of an infectious bacterial artificial chromosome clone of a pseudorabies virus variant: reconstituted virus exhibited wild-type properties in vitro and in vivo. J Virol Method 259:106-115

33. Yin Y, Xu Z, Liu X, Li P, Yang F, Zhao J, Fan Y, Sun X, Zhu L (2017) A live gl/ $\mathrm{gE}$-deleted pseudorabies virus (PRV) protects weaned piglets against lethal variant PRV challenge. Virus Gen 53:565-572

34. Wiedenheft B, Sternberg SH, Doudna JA (2012) RNA-guided genetic silencing systems in bacteria and archaea. Nature 482:331-338

35. Concordet JP, Haeussler M (2018) CRISPOR: intuitive guide selection for CRISPR/Cas9 genome editing experiments and screens. Nucleic Acids Res 46:W242-W245

36. Smith GA, Enquist LW (1999) Construction and transposon mutagenesis in Escherichia coli of a full-length infectious clone of pseudorabies virus, an alphaherpesvirus. J Virol 73:6405-6414

37. Quint W, Gielkens A, Van Oirschot J, Berns A, Cuypers HT (1987) Construction and characterization of deletion mutants of pseudorabies virus: a new generation of "live" vaccines. J Gen Virol 68:523-534

38. Lamote JAS, Kestens M, Van Waesberghe C, Delva J, De Pelsmaeker S, Devriendt B, Favoreel HW (2017) The pseudorabies virus glycoprotein $\mathrm{gE} / \mathrm{gl}$ complex suppresses type I interferon production by plasmacytoid dendritic cells. J Virol 91:e02276-e2316

39. Johnson DC, Webb M, Wisner TW, Brunetti C (2001) Herpes simplex virus $\mathrm{gE} / \mathrm{gl}$ sorts nascent virions to epithelial cell junctions, promoting virus spread. J Virol 75:821-833

40. Diwaker D, Murray JW, Barnes J, Wolkoff AW, Wilson DW (2020) Deletion of the pseudorabies Virus gE/gI-US9p complex disrupts kinesin KIF1A and $\mathrm{KIF5}$ C recruitment during egress, and alters the properties of microtubule-dependent transport in vitro. PLoS Pathog 16:e1008597

41. Lund EG, Kerr TA, Sakai J, Li WP, Russell DW (1998) CDNA cloning of mouse and human cholesterol 25-hydroxylases, polytopic membrane proteins that synthesize a potent oxysterol regulator of lipid metabolism. J Biol Chem 273:34316-34327

42. Kandutsch AA, Chen HW, Heiniger HJ (1978) Biological-activity of some oxygenated sterols. Science 201:498-501
43. Hannedouche S, Zhang J, Yi T, Shen W, Nguyen D, Pereira JP, Guerini D, Baumgarten BU, Roggo S, Wen B, Knochenmuss R, Noel S, Gessier F, Kelly LM, Vanek M, Laurent S, Preuss I, Miault C, Christen I, Karuna R, Li W, Koo DI, Suply T, Schmedt C, Peters EC, Falchetto R, Katopodis A, Spanka C, Roy MO, Detheux M, Chen YA, Schultz PG, Cho CY, Seuwen K, Cyster JG, Sailer AW (2011) Oxysterols direct immune cell migration via EBI2. Nature 475:524-527

44. Bauman DR, Bitmansour AD, McDonald JG, Thompson BM, Liang G, Russell DW (2009) 25-Hydroxycholesterol secreted by macrophages in response to toll-like receptor activation suppresses immunoglobulin A production. Proc Natl Acad Sci U S A 106:16764-16769

45. Reboldi A, Dang EV, McDonald JG, Liang G, Russell DW, Cyster JG (2014) Inflammation. 25-Hydroxycholesterol suppresses interleukin-1-driven inflammation downstream of type I interferon. Science 345:679-684

46. Pokharel SM, Shil NK, GC JB, Colburn ZT, Tsai SY, Segovia JA, Chang TH, Bandyopadhyay S, Natesan S, Jones JCR, Bose S (2019) Integrin activation by the lipid molecule 25 -hydroxycholesterol induces a proinflammatory response. Nat Commun 10:1482

47. Liu SY, Aliyari R, Chikere K, Li G, Marsden MD, Smith JK, Pernet O, Guo H, Nusbaum R, Zack JA, Freiberg AN, Su L, Lee B, Cheng G (2013) Interferon-inducible cholesterol-25-hydroxylase broadly inhibits viral entry by production of 25-hydroxycholesterol. Immunity 38:92-105

48. Wang J, Zeng L, Zhang L, Guo ZZ, Lu SF, Ming SL, Li GL, Wan B, Tian KG, Yang GY, Chu BB (2017) Cholesterol 25-hydroxylase acts as a host restriction factor on pseudorabies virus replication. J Gen Virol 98:1467-1476

49. Xu A, Qin C, Lang Y, Wang M, Lin M, Li C, Zhang R, Tang J (2015) A simple and rapid approach to manipulate pseudorabies virus genome by CRISPR/Cas9 system. Biotechnol Lett 37:1265-1272

50. Tang N, Zhang Y, Pedrera M, Chang P, Baigent S, Moffat K, Shen Z, Nair $V$, Yao Y (2018) A simple and rapid approach to develop recombinant avian herpesvirus vectored vaccines using CRISPR/Cas9 system. Vaccine 36:716-722

51. Ribeiro EA, Nectow AR, Pomeranz LE, Ekstrand MI, Koo JW, Nestler EJ (2019) Viral labeling of neurons synaptically connected to nucleus accumbens somatostatin interneurons. PLoS One 14:e213476

52. Wang J, Li GL, Ming SL, Wang CF, Shi LJ, Su BQ, Wu HT, Zeng L, Han YQ, Liu ZH, Jiang DW, Du YK, Li XD, Zhang GP, Yang GY, Chu BB (2020) BRD4 inhibition exerts anti-viral activity through DNA damage-dependent innate immune responses. PLoS Pathog 16:e1008429

53. Wang J, Wang CF, Ming SL, Li GL, Zeng L, Wang MD, Su BQ, Wang Q, Yang GY, Chu BB (2020) Porcine IFITM1 is a host restriction factor that inhibits pseudorabies virus infection. Int J Biol Macromol 151:1181-1193

54. Mulder WA, Jacobs L, Priem J, Kok GL, Wagenaar F, Kimman TG, Pol JM (1994) Glycoprotein gE-negative pseudorabies virus has a reduced capability to infect second-and third-order neurons of the olfactory and trigeminal routes in the porcine central nervous system. J Gen Virol 75:3095-3106

55. Tang YD, Liu JT, Fang QQ, Wang TY, Sun MX, An TQ, Tian ZJ, Cai XH (2016) Recombinant pseudorabies virus (PRV) expressing firefly luciferase effectively screened for CRISPR/Cas9 single guide RNAs and antiviral compounds. Viruses 8:90

56. Kovacs F, Mettenleiter TC (1991) Firefly luciferase as a marker for herpesvirus (pseudorabies virus) replication in vitro and in vivo. J Gen Virol 72:2999-3008

57. Shawli GT, Adeyemi OO, Stonehouse NJ, Herod MR (2019) The oxysterol 25-hydroxycholesterol inhibits replication of murine norovirus. Viruses 11:97

58. Moog C, Aubertin AM, Kirn A, Luu B (1998) Oxysterols, but not cholesterol, inhibit human immunodeficiency virus replication in vitro. Antivir Chem Chemother 9:491-496

59. Qin FX, Jiang CY, Jiang T, Cheng G (2015) New targets for controlling ebola virus disease. Natl Sci Rev 2:266-267

60. Teissier E, Pécheur El (2007) Lipids as modulators of membrane fusion mediated by viral fusion proteins. Eur Biophys J 36:887-899

61. Zhao J, Chen J, Li M, Chen M, Sun C (2020) Multifaceted functions of $\mathrm{CH} 25 \mathrm{H}$ and $25 \mathrm{HC}$ to modulate the lipid metabolism, immune responses, and broadly antiviral activities. Viruses 12:727 
62. Lange Y, Ye J, Strebel F (1995) Movement of 25-hydroxycholesterol from the plasma membrane to the rough endoplasmic reticulum in cultured hepatoma cells. J Lipid Res 36:1092-1097

63. Desplanques AS, Nauwynck HJ, Vercauteren D, Geens T, Favoreel HW (2008) Plasma membrane cholesterol is required for efficient pseudorabies virus entry. Virology 376:339-345

64. Bi Y, Sun L, Gao D, Ding C, Li Z, Li Y, Cun W, Li Q (2014) High-efficiency targeted editing of large viral genomes by RNA-guided nucleases. PLoS Pathog 10:e1004090

65. Tang YD, Liu JT, Wang TY, An TQ, Sun MX, Wang SJ, Fang QQ, Hou LL, Tian ZJ, Cai XH (2016) Live attenuated pseudorabies virus developed using the CRISPR/Cas9 system. Virus Res 225:33-39

66. Guo JC, Tang YD, Zhao K, Wang TY, Liu JT, Gao JC, Chang XB, Cui HY, Tian ZJ, Cai XH, An TQ (2016) Highly efficient CRISPR/Cas9-mediated homologous recombination promotes the rapid generation of bacterial artificial chromosomes of pseudorabies virus. Front Microbiol 7:2110
67. Liang X, Sun L, Yu T, Pan Y, Wang D, Hu X, Fu Z, He Q, Cao G (2016) A CRISPR/Cas9 and Cre/Lox system-based express vaccine development strategy against re-emerging pseudorabies virus. Sci Rep 6:19176

68. Tang YD, Guo JC, Wang TY, Zhao K, Liu JT, Gao JC, Tian ZJ, An TQ, Cai XH (2018) CRISPR/Cas9-mediated 2-sgRNA cleavage facilitates pseudorabies virus editing. FASEB J 32:4293-4301

69. Van Cleemput J, Koyuncu OO, Laval K, Engel EA, Enquist LW (2021) CRISPR/Cas9-constructed pseudorabies virus mutants reveal the importance of UL13 in alphaherpesvirus escape from genome silencing. J Virol 95:e02286--e2320

\section{Publisher's Note}

Springer Nature remains neutral with regard to jurisdictional claims in published maps and institutional affiliations.
Ready to submit your research? Choose BMC and benefit from:

- fast, convenient online submission

- thorough peer review by experienced researchers in your field

- rapid publication on acceptance

- support for research data, including large and complex data types

- gold Open Access which fosters wider collaboration and increased citations

- maximum visibility for your research: over $100 \mathrm{M}$ website views per year

At BMC, research is always in progress.

Learn more biomedcentral.com/submissions 